\title{
Applicable Conditions for Alleviation of Subjective and Cardiovascular Loads in the Local Cold Tolerance Test
}

\author{
Shin-ichi SAWADA and Sohei YAMAMOTO \\ National Institute of Industrial Health, \\ 21-1, Nagao, 6-chome, Tama-ku, Kawasaki, 214 Japan
}

(Received May 15, 1984)

\begin{abstract}
Cold-induced vasodilatation (CIVD) and systemic cardiovascular responses due to local finger cooling were studied in 10 healthy subjects at different room $\left(22\right.$ and $\left.30^{\circ} \mathrm{C}\right)$, water $\left(0,5\right.$, and $\left.10^{\circ}\right)$ temperatures and immersion times ( 5 to $30 \mathrm{~min})$. The skin temperature of the immersed finger, blood pressure, and heart rate were measured before and during the experiments. Conspicuous CIVD comparable to that at the $0^{\circ} \mathrm{C}$ test could be obtained even at a water temperature of 5 or $10^{\circ} \mathrm{C}$ by a rise in room temperature. Under such room and water temperature conditions where marked CIVD appeared, the order of the degree of CIVD in the individuals was almost the same, although the CIVD response was infiuenced by changes in the room and water temperatures. Furthermore, the order of the mean skin temperature (MSTi) calculated by shortening the immersion time every $1 \mathrm{~min}$ remained extremely stable $(r>0.90)$ even by more than a 20 -min reduced immersion time, especially at a water temperature of $5^{\circ} \mathrm{C}$. During several minutes after the start of immersion, maximal changes in blood pressure and discomfort due to cold were observed. The degree of these systemic loads in the subjects was reduced with rise in the water temperature. It is concluded that the current local cold tolerance test for $30 \mathrm{~min}$ at $0^{\circ} \mathrm{C}$ can be substituted sufficiently by a $5^{\circ} \mathrm{C}$ test for 10 to $15 \mathrm{~min}$, and partly even by the $10^{\circ} \mathrm{C}$ test with the limitation that only MSTi and AT are available as an indicator of the local cold tolerance at higher environmental temperatures.
\end{abstract}

Key words: Cold-induced vasodilatation (CIVD)-Local cold tolerance testCardiovascular load-Cold pain-Individual difference

\section{INTRODUCTON}

Frostbite is one of the typical injuries caused by occupational exposure to extreme cold or by accidents in cold weather seasons. In Japan, the number of cases judged to be job-related amounted to 43 to 48 each year in the period from 1973 to $1977 .{ }^{1)}$ As a countermeasure for preventing cold injuries, it is of course important to use protection against the cold. Even so, individual differences in local cold tolerance (resistance against frostbite) must be taken into consideration from the viewpoint of occupational health. 
The response of cold-induced vasodilation (CIVD), which Lewis ${ }^{2}$ first described as "hunting reaction", has been found to be related to the severity of cold injury;;-5) those with a higher response are less susceptible to frostbite and vice versa. Yoshimura and Iida $^{4}$ developed a local cold tolerance test on the basis of this CIVD observed in human fingers, and Nakamura et al. $^{(6)}$ subsequently modified part of the evaluation method used in this test. Current tests are, however, performed at a water temperature of $0^{\circ} \mathrm{C}$ with an immersion time of $30 \mathrm{~min}$. Finger immersion under such test conditions is very painful, and can induce fainting in some subjects. It is clear therefore that the present test is not applicable as a screening test in the field of industrial health both as regards the temperaure and time of cold exposure. It is desirable that a simplified and painless method be developed which can serve as a local cold tolerance test.

Local cold water immersion of the hand or finger induces systemic cardiovascular responses as is well known in the cold pressor test, ${ }^{\tau}$ ) as well as CIVD responses. Since these responses reflect the loads to the circulatory systems of the subjects, it is also necessary to reassess the present tests from this viewpoint.

We previously described the characteristics of CIVD at different room and water temperatures and immersion times in brief. ${ }^{8)}$ In this paper, we report further information concerning the CIVD responses under the same conditions in addition to the systemic cardiovascular responses induced by cold water immersion. From the results obtained, we examine whether a 5 or $10^{\circ} \mathrm{C}$ test of less than $30 \mathrm{~min}$ can be substituted for $0^{\circ} \mathrm{C}$ tests of $30 \mathrm{~min}$ of local cold tolerance.

\section{SubJeCts AND Methods}

Two kinds of experiments were conducted in the afternoon using 10 healthy male and female subjects (average age 21.3 years) in a climate chamber maintained at two different room temperatures of $30^{\circ} \mathrm{C}$ (the high environmental temperature experiment, " $\mathrm{HE} "$ ) and $22^{\circ} \mathrm{C}$ (the low environmental temperature experiment, "LE").

In each experiment, the subjects sat in a chair and immersed their left middle finger up to its base for $30 \mathrm{~min}$ in a cold water bath. Three series of observations were made at water temperatures of 0,5 , and $10^{\circ} \mathrm{C}$, successively with 40-min intervals. To keep the cold exposure conditions constant, we devised a new type of cold water bath as shown in Fig. 1. In this method, cold water controlled at the given temperature was exposed directly to the immersed finger at a $5 \mathrm{liter} / \mathrm{min}$ flow rate, so minimizing the thermal boundary layer produced by heat loss from the finger and ensuring a constant water temperature close to the immersed finger.

The skin temperature of the immersed finger was measured continuously using a copper-constantan thermocouple attached to the back of the middle phalanx of the finger. The systolic and diastolic blood pressures and heart rate were monitored every $1 \mathrm{~min}$ and every $30 \mathrm{sec}$, respectively. 


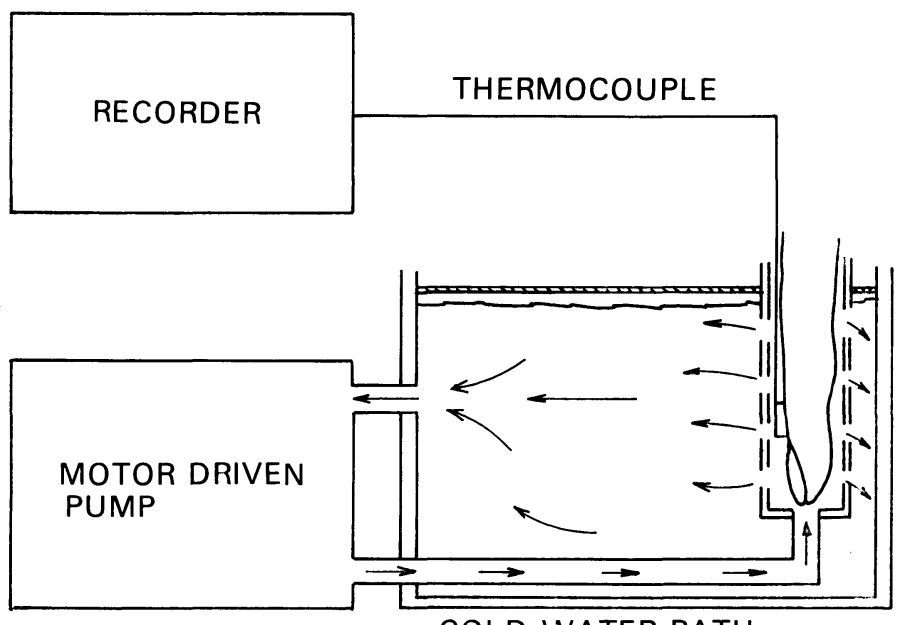

COLD WATER BATH

Fig. 1. Schematic diagram of the cold exposure method used in the present experiments.

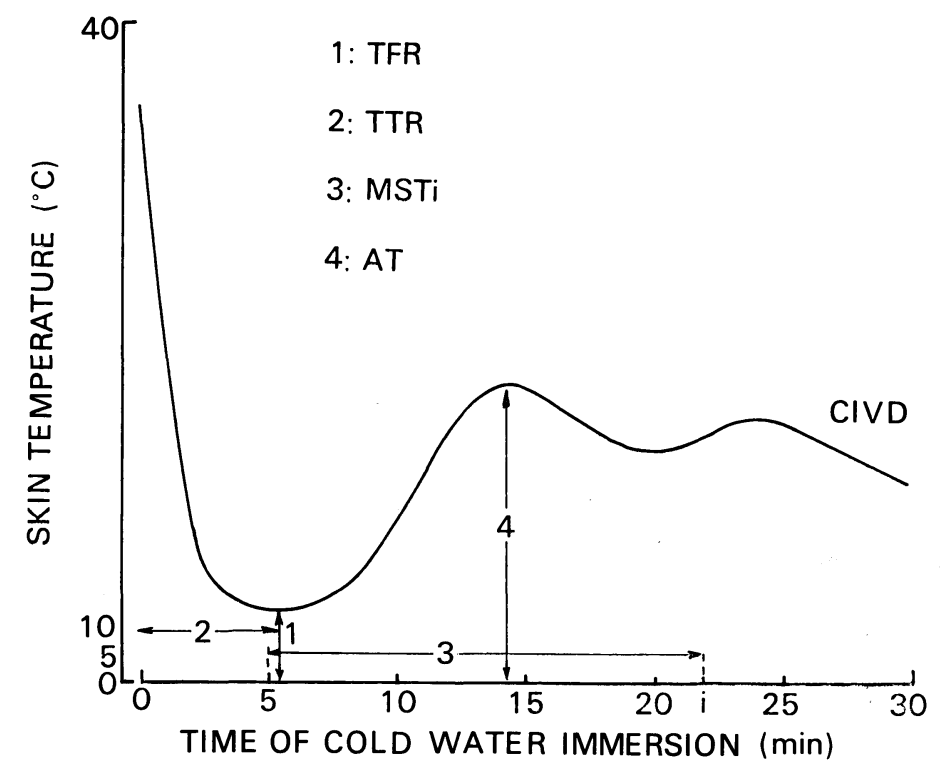

Fig. 2. Typical response pattern of CIVD and four indices (TFR, TTR, MSTi, and AT) of local cold tolerance.

Immediately after completion of each cold exposure, the discomfort of the cold pain was reported on a 5-point scale (1: none, 2: a little painful, 3: painful, 4: very painful, 5: extremely painful). For comparison of the degree of and individual differences in CIVD, the following indices of the reaction were selected as defined in our previous report. ${ }^{8)}$ TFR (temperature of the first rise after 
immersion), TTR (time of the first temperature rise after immersion), AT (amplitude of the temperature reaction), and MSTi $(5 \leqq i \leqq 30$ min) (mean skin temperature $5 \mathrm{~min}$ to $\mathrm{i}$ min following the immersion). MST30 was equal to MST used in the current test (Fig. 2). Therefore, those with higher TFR, MSTi, and AT values and with lower TTR were regarded as being of higher local cold tolerance, and vice versa.

To evaluate the systemic cardiovascular loads, the following variables were selected from the blood pressure and heart rate recordings: SP (systolic blood pressure), DP (diastolic blood pressure), HR (heart rate), and CW (cardiac work load index). This index was calculated from the following formula: $\mathrm{CW}=$ $\mathrm{HR} \times \mathrm{SP} / 100$.

The wilcoxon matched-pairs signed-ranks test was employed when differences between different room $\left(22\right.$ and $\left.30^{\circ} \mathrm{C}\right)$ and water $\left(0,5\right.$, and $\left.10^{\circ} \mathrm{C}\right)$ temperatures were compared with regard to the response of each of the CIVD indices, SP, DP, $\mathrm{HR}, \mathrm{CW}$, and discomfort of cold pain.

\section{RESUlts}

Fig. 3 shows the time course of a typical pattern of CIVD and systemic cardicvascular responses in one subject who participated in the experiment at $0^{\circ} \mathrm{C}$ water and $30^{\circ} \mathrm{C}$ room temperatures. A CIVD response appeared several minutes after

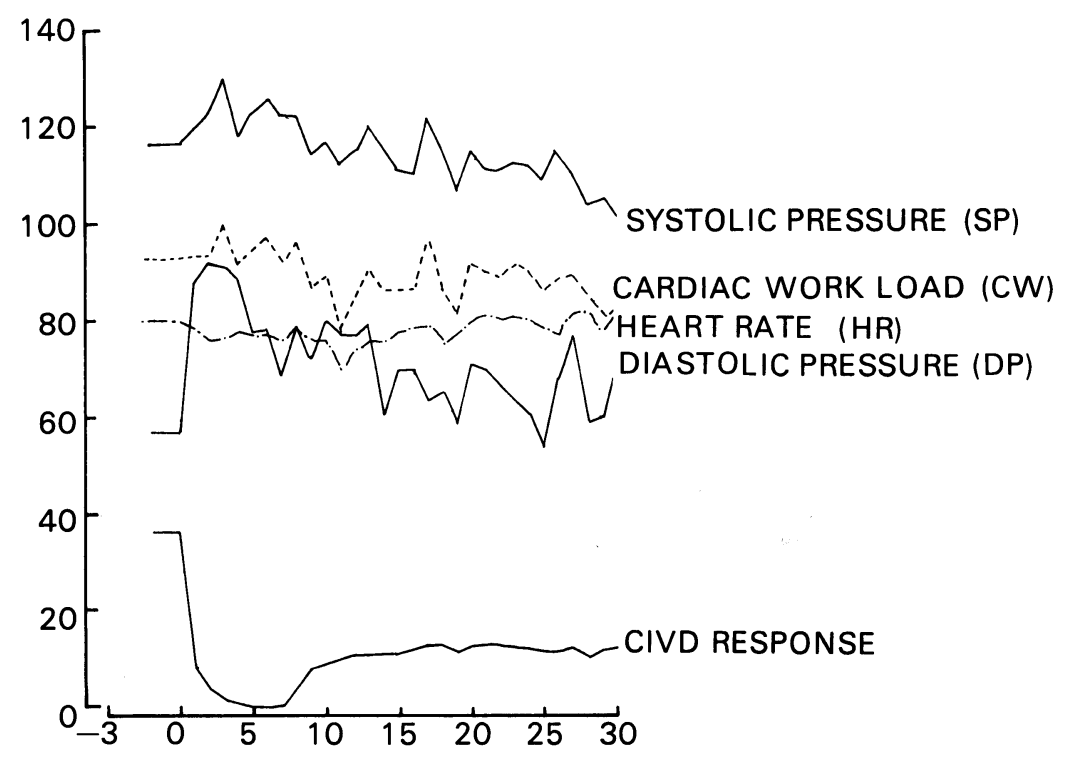

TIME OF COLD WATER IMMERSION ( $\mathrm{min}$ )

Fig. 3. Example of the time course of local CIVD and systemic cardiovascular responses in a subject at $0^{\circ} \mathrm{C}$ water and $30^{\circ} \mathrm{C}(\mathrm{HE})$ room temperature. 
the start of immersion. SP and DP rapidly increased immediately after the start of immersion, and reached maximal levels within several minutes. In contrast, HR showed no remarkable change. $\mathrm{CW}$ thus underwent an increasing change similar to the change in SP or DP, and revealed a maximal increase before CIVD occurred. These response patterns were almost identical at any other water and room temperatures.

Fig. 4 gives average values for each of the indices of CIVD for all subjects at different room and water temperatures. At all water temperatures, TFR, MST30, and AT were larger and TTR was smaller under HE compared to LE, indicating an increase in CIVD responses. That is, under HE conspicuous CIVD appeared at all water temperatures, while under LE poor CIVD was observed and in some cases, no response was seen at a water temperature of $10^{\circ} \mathrm{C}$.

Fig. 5 presents one example of the CIVD response patterns in the same individual at water temperatures of 0,5 and $10^{\circ} \mathrm{C}$ under $\mathrm{HE}$ conditions. The CIVD patterns were not necessarily similar between different water temperatures; shortening of TTR and increase of TFR were found at 5 or $10^{\circ} \mathrm{C}$ compared to
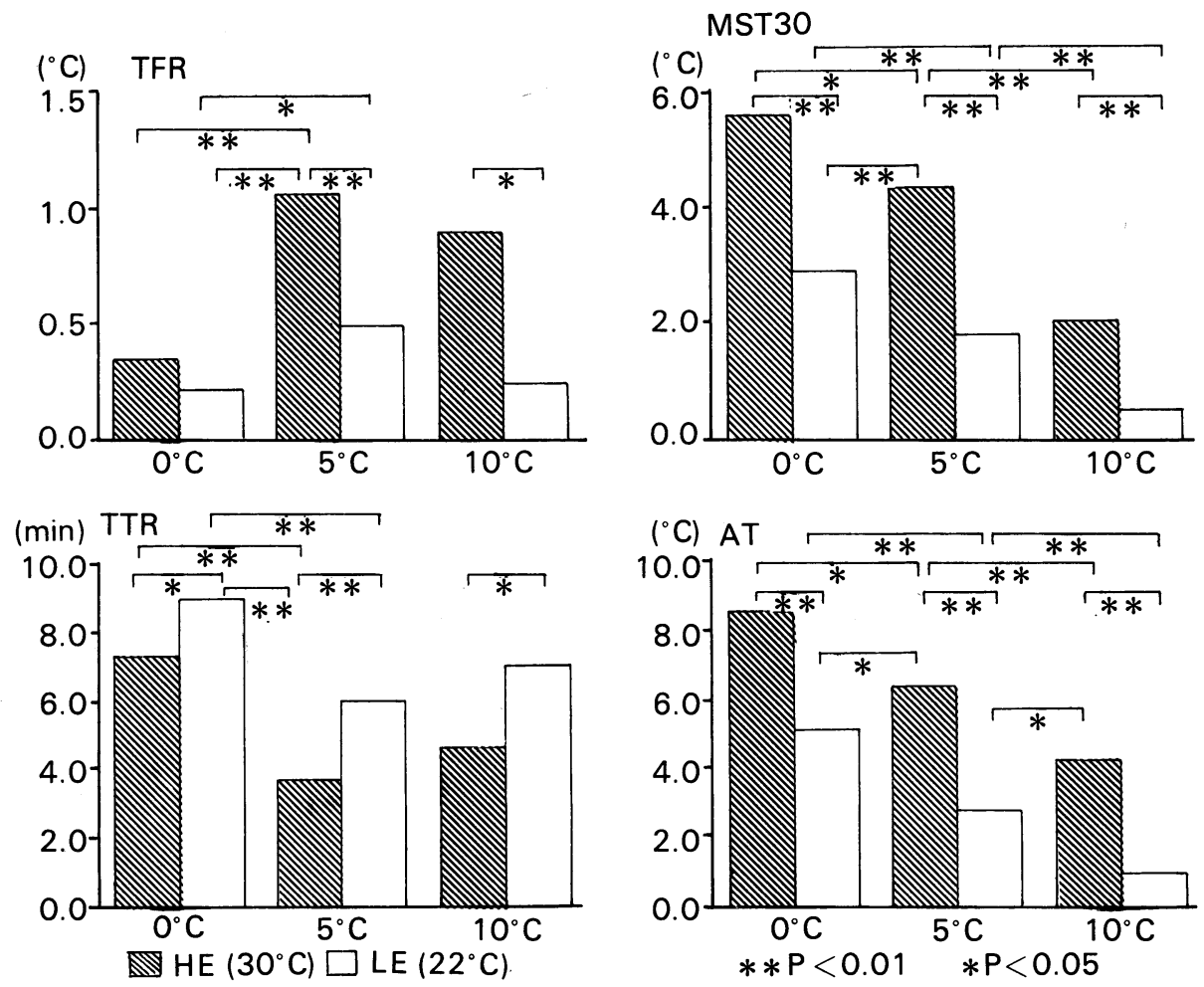

Fig. 4. Average values of four indices (TFR, TTR, MST30, and At) in CIVD at different room $\left(22^{\circ} \mathrm{C}<=\mathrm{LE}>, 30^{\circ} \mathrm{C}<=\mathrm{HE}>\right)$ and water $\left(0^{\circ} \mathrm{C}, 5^{\circ} \mathrm{C}\right.$, and $\left.10^{\circ} \mathrm{C}\right)$ temperatures.

Significance level: $* * \mathrm{P}<0.01, * \mathrm{P}<0.05$. 


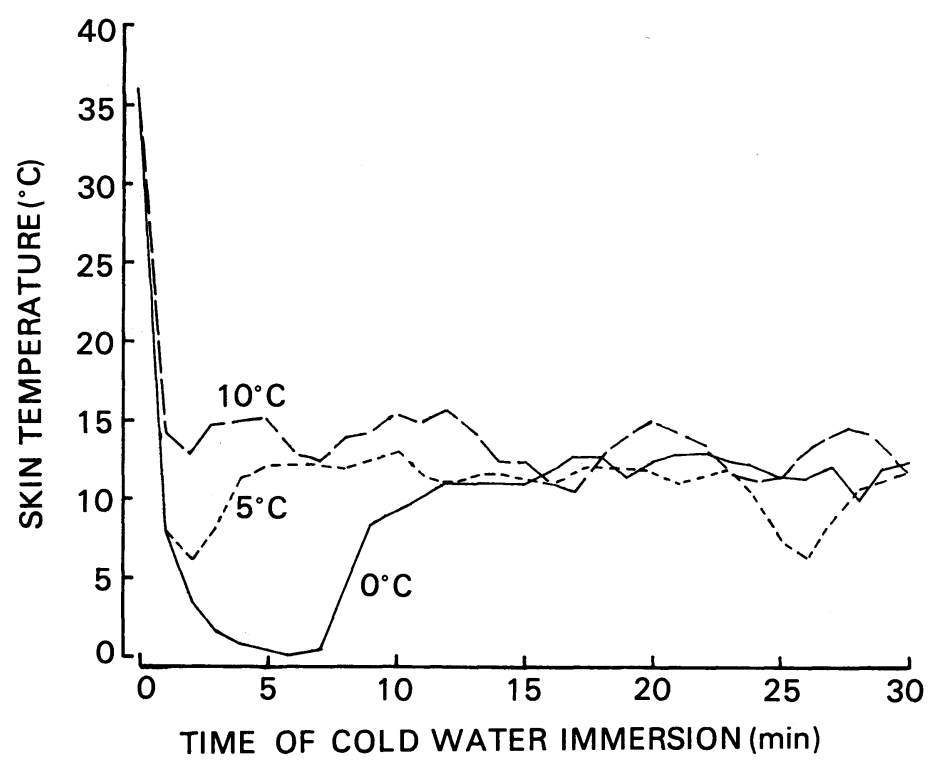

Fig. 5. Examples of CIVD responses in a subject at different water temperatures of $0^{\circ} \mathrm{C}, 5^{\circ} \mathrm{C}$, and $10^{\circ} \mathrm{C}$ under $30^{\circ} \mathrm{C}$ room temperature (HE) conditions.

those at $0^{\circ} \mathrm{C}$, while MST30 and AT decreased with rise in the water temperature. Nevertheless, as mentioned above and shown in Fig. 3, the degree of CIVD in all the subjects increased under HE conditions. As a result, MST30 and AT at water temperatures of 5 and $10^{\circ} \mathrm{C}$ were found to be greater under $\mathrm{HE}$ than those at 0 and $5^{\circ} \mathrm{C}$ under LE conditions, respectively.

Correlation coefficients for the indices of CIVD between HE and LE, which may explain the regularity in the order of individual differences, are listed in Table 1. Relatively high correlation coefficients at $0^{\circ} \mathrm{C}$, and especially significant ones at a water temperature of $5^{\circ} \mathrm{C}$ were obtained for each of the indices of CIVD between room temperatures of 22 and $30^{\circ} \mathrm{C}$, although low correlation coefficients were found at a water temperature of $10^{\circ} \mathrm{C}$. Judging from the significantly high correlation between water temperatures of 0 and $5^{\circ} \mathrm{C}$ presented in Table 2 , the

Table 1. Correlation coefficients of the order of individual differences in each of the indices of CIVD between different room temperatures (LExHE)

\begin{tabular}{lrllll}
\hline & & TFR & TTR & MST $_{30}$ & \multicolumn{1}{c}{ AT } \\
\hline \multirow{2}{*}{ R LE $\times$ HE } & $0^{\circ} \mathrm{C}$ & 0.518 & 0.398 & 0.518 & 0.504 \\
& $5^{\circ} \mathrm{C}$ & $0.754^{* *}$ & 0.515 & $0.671^{*}$ & $0.658^{*}$ \\
& $10^{\circ} \mathrm{C}$ & 0.028 & -0.065 & 0.136 & 0.330 \\
\hline
\end{tabular}

$* \mathrm{P}<0.05, * * \mathrm{P}<0.01$ 
Table 2. Correlation coefficients of the order of individual differences in each of the indices of CIVD between different water temperatures $\left(0^{\circ} \mathrm{C} \times 5^{\circ} \mathrm{C}, 0^{\circ} \mathrm{C} \times 10^{\circ} \mathrm{C}\right)$

\begin{tabular}{clcllc}
\hline & & TFR & \multicolumn{1}{c}{ TTR } & \multicolumn{1}{c}{$\mathrm{MST}_{30}$} & \multicolumn{1}{c}{$\mathrm{AT}$} \\
\hline \multirow{2}{*}{$\mathrm{LE}\left(22^{\circ} \mathrm{C}\right)$} & $\mathrm{R} 0^{\circ} \mathrm{C} \times 10^{\circ} \mathrm{C}$ & $0.627^{*}$ & $0.897^{* *}$ & $0.923^{* *}$ & $0.777^{*}$ \\
& $\mathrm{R} 0^{\circ} \mathrm{C} \times 5^{\circ} \mathrm{C}$ & -0.217 & 0.366 & 0.109 & -0.038 \\
$\mathrm{HE}\left(30^{\circ} \mathrm{C}\right)$ & $\mathrm{R}_{0}{ }^{\circ} \mathrm{C} \times 10^{\circ} \mathrm{C}$ & 0.404 & $0.740^{* *}$ & $0.604^{*}$ & $0.661^{*}$ \\
& $\mathrm{R}_{0}{ }^{\circ} \mathrm{C} \times 5^{\circ} \mathrm{C}$ & 0.260 & -0.007 & $0.629^{*}$ & $0.605^{*}$ \\
\hline
\end{tabular}

$* \mathrm{P}<0.05, * * \mathrm{P}<0.01$

individual differences in most indices of CIVD are apparently almost in the same order under both $\mathrm{HE}$ and LE conditions, even though the water temperature rises from 0 to $5^{\circ} \mathrm{C}$. On the other hand, a significant correlation in the order of individual differences between water temperatures of 0 and $10^{\circ} \mathrm{C}$ was found only for MST30 and AT under HE conditions, and there was no such correlation under LE conditions.

The stability of the order of individual differences was also investigated between MST30 as defined above and MSTi $(5 \leqq i \leqq 29)$ calculated by shortening the immersion time every $1 \mathrm{~min}$ from the usual immersion time $(30 \mathrm{~min})$. Fig. 6 shows a correlogram between MST30 and MST20 at a water temperature of $5^{\circ} \mathrm{C}$ under both $\mathrm{HE}$ and LE conditions. The high linearity seen in this figure

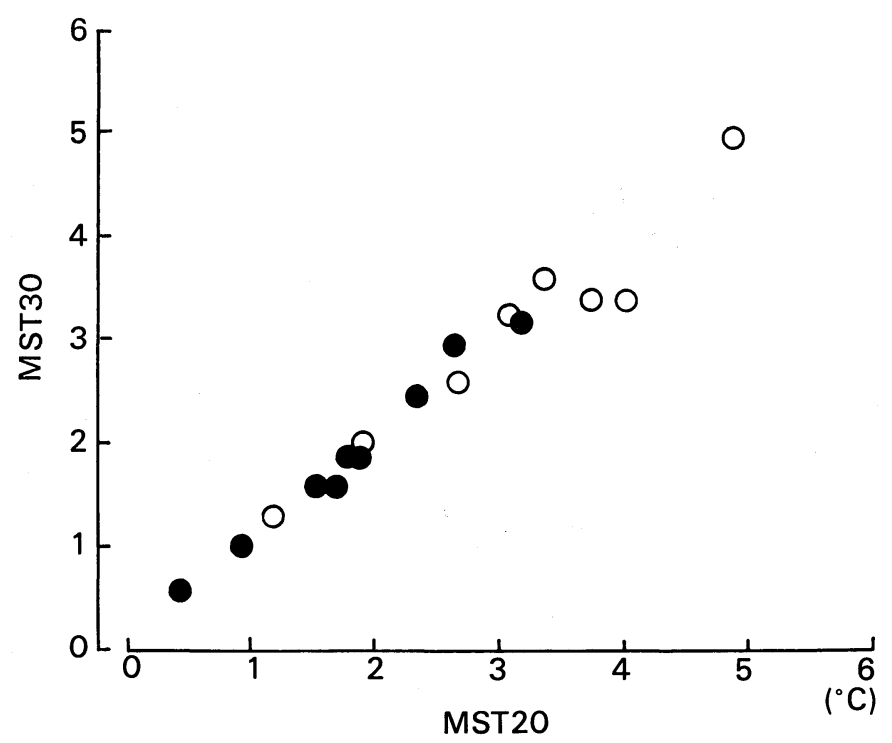

Fig. 6. Correlogram between MST30 and MST20 by room temperature.

The open circles $(O)$ represent samples obtained at $30^{\circ} \mathrm{C}(\mathrm{HE})$; the closed circles (๑), at $22^{\circ} \mathrm{C}(\mathrm{LE})$. 


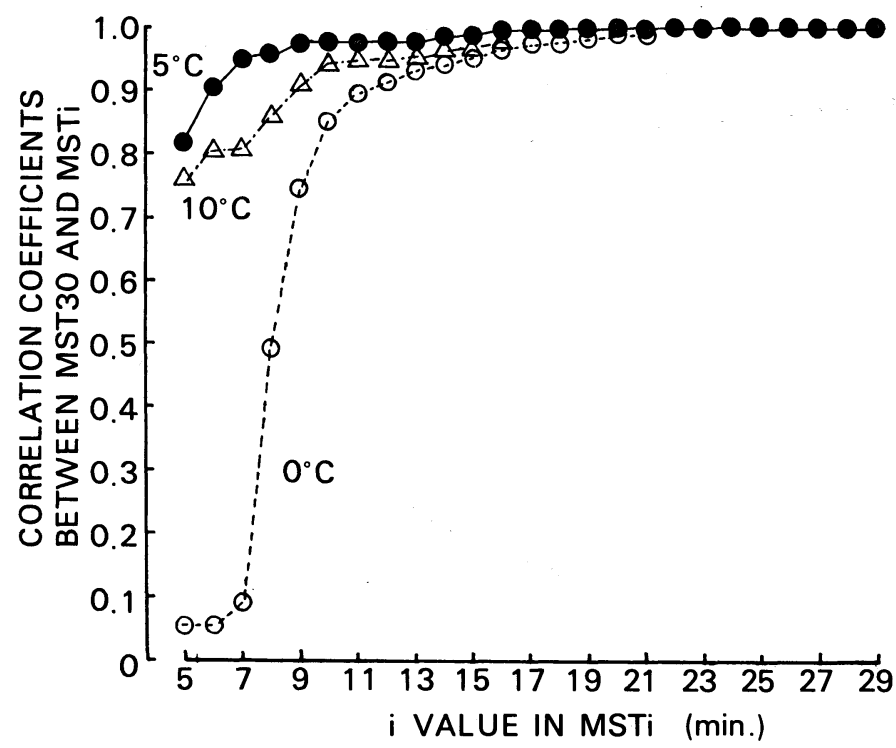

Fig 7. Correlation coefficients between MST30 and MSTi $(5 \leqq i \leqq 29)$ water temperature $\left(\bigcirc: 0^{\circ} \mathrm{C}, \bigcirc: 5^{\circ} \mathrm{C}, \triangle: 10^{\circ} \mathrm{C}\right)$.

indicates that the order of the degree of MSTi in individuals remained almost constant despite shortening of the immersion time by $10 \mathrm{~min}$. The results of calculation of the correlation coefficients between MST30 and MSTi $(5 \leqq i \leqq 29)$ are shown by water temperature in Fig. 7. At each of the three different water temperatures, even more than 20 min shortening of the immersion time maintained the high correlation coefficients at above 0.9 . Especially at a water temperature of $5^{\circ} \mathrm{C}$, the degree of correlation was found to be maximal and the correlation coefficients between MST6 and MST30 were about 0.9 .

The maximal percent increases in systemic cardiovascular responses observed within $20 \mathrm{~min}$ after the start of immersion and discomfort of cold pain, were averaged for all subjects are illustrated in Fig. 8. Under both $\mathrm{HE}$ and LE conditions, the percent increase in systolic and diastolic blood pressure appeared to decrease as the water temperature rose. $\mathrm{HR}$ was significantly high at 0 and $10^{\circ} \mathrm{C}$ under LE, but there were no definite tendencies under any other water and room temperature conditions. $\mathrm{CW}$ was found to be significantly changed at between 0 and $5^{\circ} \mathrm{C}$ under both $\mathrm{HE}$ and $\mathrm{LE}$ conditions. The degree of pain complained of by each subject was significantly reduced with rise in the water temperature under both HE and LE conditions.

\section{Discussion}

Yoshimura $^{9)}$ suggested that satisfactory results could not be obtained in $5^{\circ} \mathrm{C}$ 

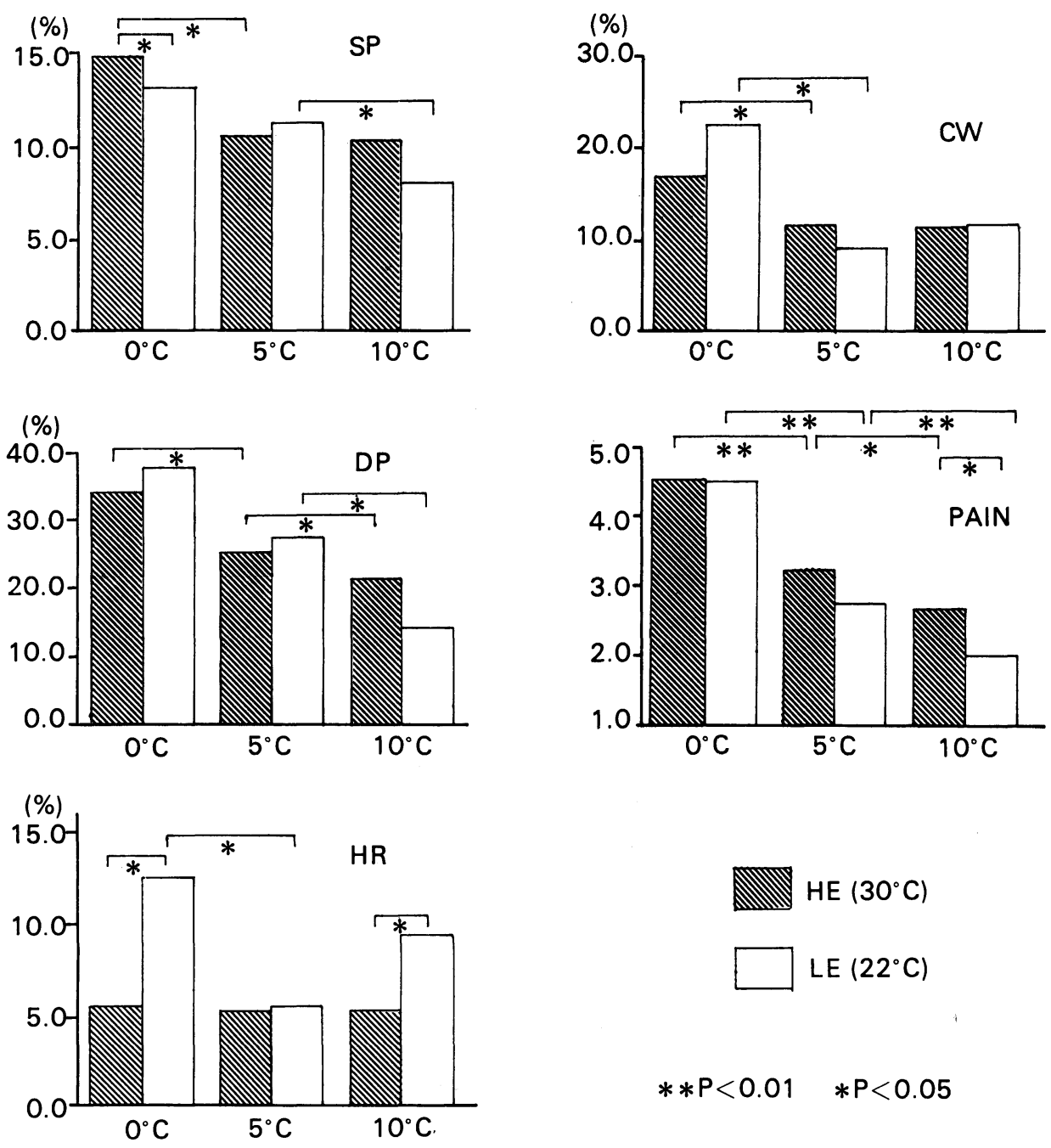

Fig. 8. Average values of the maximal percent increases in systemic cardiovascular responses $(S P, D P, H R$, and $C W$ ) observed within 20 min after the start of immersion and discomfort of cold pain (PAIN) at different room $\left(22^{\circ} \mathrm{C}<=\right.$ $\left.\mathrm{LE}>, 30^{\circ} \mathrm{C}<=\mathrm{HE}>\right)$ and water $\left(0^{\circ} \mathrm{C}, 5^{\circ} \mathrm{C}\right.$ and $\left.10^{\circ} \mathrm{C}\right)$ temperatures.

Significance level: ${ }^{* *} \mathrm{P}<0.01,{ }^{*} \mathrm{P}<0.05$.

tests of local cold tolerance as compared to $0^{\circ} \mathrm{C}$ tests. Watanuki, ${ }^{10)}$ observing the CIVD response during cold air exposure, pointed out that tests at $0^{\circ} \mathrm{C}$ with ice water would be preferable when it was necessary to observe the typical CIVD response. These facts might represent part of the reason why in most local cold tolerance tests previously performed in laboratory or field studies, the test 
conditions of $30 \mathrm{~min}$ at $0^{\circ} \mathrm{C}$ have been adopted. ${ }^{11)}$ Nevertheless, when the CIVD response is intended to be used as a screening test for industrial health, or as a biometer ${ }^{12,13)}$ in ecological field studies, the current method appears to be unpracticable both as regards temperature and time of cold water immersion. This is because the number of participants in the test is large and they consist of younger or elder males or females.

For the purpose of investigating the ageing effect on CIVD, Spurr ${ }^{14)}$ previously used the $10^{\circ} \mathrm{C}$ test, and the duration of immersion was varied at 10,20 , and $30 \mathrm{~min}$ for the aged, children and young adults, respectively. In recent studies, ${ }^{15-17)}$ some effort has been made to lighten the loads imposed on the subjects participating in the test by shortening the immersion time from 30 to 20 min or adopting the $5^{\circ} \mathrm{C}$ test for $10 \mathrm{~min}$. However, these attempts, which formally followed the previous test criteria or adopted their own method of evaluation, were not performed on the basis of experimental evidence which confirmed that each of them could substitute for the usual method. Mathew ${ }^{18)}$ investigated this point in monkeys, but no studies have been reported for human subjects.

The present results indicated that the degree of CIVD response did not necessarily decrease as the water temperature rose: at a water temperature of $5^{\circ} \mathrm{C}$, TFR was maximal and TTR was minimal under both HE and LE conditions. With rise of the water temperature, the MST30 and AT values decreased and few responses in CIVD were observed at $10^{\circ} \mathrm{C}$ under the LE. However, since the degree of CIVD increased at every water temperature under HE, MST30 and AT at 5 and $10^{\circ} \mathrm{C}$ are likely to be larger under $\mathrm{HE}$ than those at 0 and $5^{\circ} \mathrm{C}$ under LE, respectively. It is considered therefore that a rise in water temperature can quicken the time of CIVD occurrence and that the rise in environmntal temperature confirms a conspicuous CIVD even at water temperatures of 5 and $10^{\circ} \mathrm{C}$. Mathew ${ }^{18)}$ reported that the CIVD patterns in monkeys were almost identical between different water temperatures $\left(0\right.$ and $\left.4{ }^{\circ} \mathrm{C}\right)$, which is contradictory to our finding that higher water temperatures shortened TTR and increased TFR. The reason for this disparity is unclear at present, although it might be explained by species differences in the peripheral vasculature and its neural control.

Hirai $^{19)}$ demonstrated that in $0^{\circ} \mathrm{C}$ tests, the order of the degree of CIVD in individuals was almost the same although the CIVD response was influenced by the body heat content. In the present study, we examined the order of the degree of CIVD at water temperatures of 5 and $10^{\circ} \mathrm{C}$ as well as $0^{\circ} \mathrm{C}$ under the two temperature conditions of $\mathrm{HE}$ and $\mathrm{LE}$, which could alter the body heat content. As a result, high correlations in each of the indices of CIVD at water temperatures of both 0 and $5^{\circ} \mathrm{C}$ were obtained even when the environmental temperature changed. Furthermore, at a given environmental temperature, a rise in the water temperature from 0 to $5^{\circ} \mathrm{C}$ maintained significantly high correlations for each of the indices of CIVD.

The low correlations in the order of the indivdual differences under some 
conditions as shown in Tables 1 and 2, appeared to be due to a reduction in the absolute individual variations in CIVD indices by extreme depression of CIVD at a water temperature of $10^{\circ} \mathrm{C}$ under LE conditions. This depression of CIVD would result from the small heat content at a low environmental temperature. ${ }^{20-22)}$ Therefore, under such room and water temperature conditions as marked CIVD appeared, the order of individual differences in CIVD, especially of MST30 and AT, would be almost stable despite the change in water and room temperatures.

Concerning the immersion time, it became clear from our experimental results that the $30 \mathrm{~min}$ of the current method is longer than necessary. At any water temperature, MSTi calculated by $20 \mathrm{~min}$ shortening was shown to be highly correlated $(r>0.90)$ with the current MST30. This suggests that the degree of individual differences in the current MST30 can be predicted by comparing the MSTi calculated within several minutes after CIVD appears. The fact that higher correlations were maintained at 5 or $10^{\circ} \mathrm{C}$ than at $0^{\circ} \mathrm{C}$ appears due to the fact that CIVD occurs earlier at higher water temperatures than at $0^{\circ} \mathrm{C}$, and that at earlier stages of immersion the degree of individual differences of MSTi is detectable. Thus, insofar as the immersion time is concerned, the $5^{\circ} \mathrm{C}$ or $10^{\circ} \mathrm{C}$ condition seems more advantageous than $0^{\circ} \mathrm{C}$ since the immersion time may possibly be further shortened.

In our experiments, we measured the blood pressure, heart rate and subjective complaints of cold pain in order to compare the degree of individual cardiovascular loads and discomfort due to cold between different water and room temperatures. At any of the water and room temperatures, the blood pressure was rapidly increased immediately after the start of immersion and reached maximal levels within several minutes before CIVD appeared. At this stage, all subjects complained of cold pain. However, after this stage, where CIVD appeared, their complaints diminished and the blood pressure fell to the level shown before the start of immersion. From these observations, it is concluded that the loads experienced by the subjects during cold water immersion of the hands or fingers may be maximal for several minutes after the start of immersion and do not continue after CIVD appears. Since the complaints or systemic cardiovascular loads of the subjects are thus temporary, an immersion time of $30 \mathrm{~min}$ in situ is not necessarily problematic for carrying out a local cold tolerance test. However, a short time is better for undertaking screening tests. With rise in the water temperature, the degree of cold pain and blood pressure increase was reduced. $\mathrm{CW}$ was also decreased at higher water temperatures than at $0^{\circ} \mathrm{C}$, but there was little difference between 5 and $10^{\circ} \mathrm{C}$. As mentioned, CIVD appeared earlier at higher water temperatures than $0^{\circ} \mathrm{C}$. Since the loads on the subjects were maximal before CIVD appeared, the duration of their loads would decrease with rise of the water temperature. Based on these findings for the loads and their duration in the subjects, the $5^{\circ} \mathrm{C}$ or $10^{\circ} \mathrm{C}$ test is preferable compared to that at $0^{\circ} \mathrm{C}$. 


\section{CONCLUSION}

The present study supports the following conclusions;

1) A rise in water temperature does not necessarily lower the degree of CIVD response: a typical CIVD comparable to that at $0^{\circ} \mathrm{C}$ can be detected even at a water temperature of 5 or $10^{\circ} \mathrm{C}$ by increasing the environmental temperature or body heat content.

2) Under room and water temperature conditions where marked CIVD can be found, the order of individual differences in CIVD, especially of MST30 and $\mathrm{AT}$, is almost stable despite changes in the water and room temperatures.

3) The immersion time of $30 \mathrm{~min}$ in the usual test appears to be longer than necessary. The order of the degree of MSTi calculated by shortening the immersion time every $1 \mathrm{~min}$ remains extremely stable even with more than $20 \mathrm{~min}$ shortening of the immersion. This suggests that information comparable to the $30 \mathrm{~min}$ test can be obtained by only comparing the degree of MSTi calculated at several minutes after the CIVD rises.

4) From the above findings, it is concluded that the current $30 \mathrm{~min}$ test at $0^{\circ} \mathrm{C}$ can be substituted by a $5^{\circ} \mathrm{C}$ test for 10 to $15 \mathrm{~min}$, and even by a $10^{\circ} \mathrm{C}$ test with the limitation that only MSTi and AT are available as an indicator of the local cold tolerance at higher environmental temperatures.

\section{ACKNOWLEDGMENT}

The authors wish to thank Mr. M. Miyagawa for his invaluable advice in devising the new type of cold water bath.

\section{REFERENCES}

1) Watanabe, A. (1981). Occupational health for work under low temperatures, with sp乏cial reference to cold exposure limits, Science of Labour, 36, 4 (in Japanese).

2) Lewis, T. (1930). Observation upon the reaction of the vessels of the human skin to cold, Heart, 15, 177.

3) Mathew, L. et al. (1975). Prediciion of susceptibility to cold injury in monkeys. In "Selected Topics in Environmental Biology" (ed. B. Bhatia et al.), p. 191, Interprint Publication, New Delhi, India.

4) Yoshimura, H. and Iida, T. (1950). Studies on the reactivity of skin vessels to extreme cold, Part I, A point test on the resistance against frostbite, Jap. J. Physiol., 1, 147.

5) Iida, T. (1949). Studies of cold-induced vasodilatation response (I): On physiological meanings of CIVD response, J. Jap. Physiol. Soc., 11, 73 (in Japanese).

6) Nakamura, M. et al. (1972). On a new method for evaluation of hunting reaction as an indicator of local cold resistance, Nagasaki Med. J., 47, 180 (in Japanese).

7) Brown, G. E. (1936). Clinical tests of function of autonomic nerve systems, J. Am. Med. Assoc., 105, 353.

8) Sawada, S. and Yamamoto, S. (1983). Stability of individual difference of cold-induced 
vasodilatation response at different room and water temperatures and immersion time, Jpn. J. Ind. Health, 25, 116.

9) Yoshimura, H. (1977). Human Adaptability, p. 117, Kyoritsu Shuppan, Tokyo (in Japanese).

10) Watanuki, M. et al. (1981). Digital vascular hunting reaction to local cold in air, Jpn. J. Biometeorol., 18, 65.

11) Sawada, S. (1982). Literal Review on Cold Tolerance and Ageing, with Special Attention to its Methodology: Report for the Study on Occupational Adaptability of Elder-aged Workers, p. 65, Konenreisha Koyokaihatsu Kyokai, Tokyo (in Japanese).

12) Katsunuma, H. and Suzuki, T. (eds.) (1970). Note for Human Ecology, p. 183, Tokyo University Press, Tokyo (in Japanese).

13) Koizumi, A. (1975). Ecology for Human Survival, 3rd ed., p. 98, Kyorin Shoin, Tokyo (in Japanese).

14) Spurr, G. B. et al. (1955). The effects of age on finger temperature responses to local cooling, Amer. Heart J., 50, 551.

15) Takano, N. (1982). Simple tests of subjective tolerance and physiological responses to cold for children, Jpn. J. Biometeorol., 19, 16.

16) Moriya, K. (1982). Cold tolerance of exercise-trained men: Assessment of finger temperature and blood pressure responses to local cooling, Jpn. J. Biometeorol., 19, 10.

17) Suzuki, M. and Kimura, K. (1982). Comparative study of thermal adaptability of Japanese child in different living environment (Part 1): At the standpoint of vascular cold reaction in difference of age, sex, area, and building type of school, Jpn. J. Biometeorol., 19, 88.

18) Mathew, L. et al. (1978). Cold-induced vasodilatation response at different water bath temperatures in monkeys, Aviat. Space Environ. Med., 49, 976.

19) Hirai, K. et al. (1968). Studies on effect of heat content on the vascular hunting reaction to cold, and the reaction of women divers, J. Physiol. Soc. Jpn., 30, 12 (in Japanese).

20) Carlson, L. D. (1966). Human Adaptability and its Methodology (ed. H. Yoshimura and J. S. Weiner), p. 60, Japan Society for the Promotion of Science, Tokyo, Japan.

21) Yoshimura, H. and Iida, Y. (1952). Studies on the reactivity of skin vessels to extreme cold, Part II: Factors governing the individual difference of the reactivity or the resistance against frostbite, Jap. J. Physiol., 1, 177.

22) Yoshimura, H. and Iida, Y. (1952). Studies on the reactivity of skin vessels to extreme cold, Part III, Effect of diets on the reactivity of skin vessels to cold, Jap. J. Physiol., 2,310 . 